\title{
Organismos multilaterais e educação: as tec- nologias da informação e comunicação (TIC) em questão
}

\section{Resumo}

Daniela da Costa Britto Pereira Lima

João Ferreira de Oliveira

Universidade Federal de Goiás

Tatiane Custódio da Silva Batista

Universidade Estadual de Goiás

Este artigo analisa documentos elaborados por organismos multilaterais no período de 1990 a 2014, sobretudo, os que trazem orientações que visam determinar as políticas, os programas e as ações no campo da educação no Brasil. Busca-se compreender, em especial, como os organismos multilaterais concebem e orientam a inserção das Tecnologias da Informação e Comunicação (TIC) na educação de nosso país, tendo por base, dentre outros, a contribuição teórico-conceitual de: Dourado, Oliveira (2009); Mancebo, Maués e Chaves (2006); Libâneo (201 1; 201 2); Sguissardi (2000); Lima (2005; 2013); Ferreira (2009; 2012); Saviani (2008); Andreoli (2002). São examinados documentos direcionados às questões econômicas e educacionais de países da América Latina e Caribe, dentre os quais, o Brasil. Observa-se que há forte influência dos organismos multilaterais na educação brasileira e que, no âmbito das $T I C$, essas diretrizes apontam para a expansão da inserção e do uso dessas tecnologias em todos os níveis da educação. Essas diretrizes, ou orientações, baseiam-se em uma concepção mercantil e mecanicista das $T I C$, em detrimento de uma perspectiva que defende uma maior democratização do acesso à informação e ao conhecimento, bem como uma formação escolar mais crítica, autônoma e cidadã.

Palavras-chave: Educação. Tecnologias da informação e comunicação. Organismos multilaterais.

\section{Multilateral organizations and education: the information technology and communication (ICT) in question}

\section{Abstract}

This paper analyzes multilateral bodies of publications from 1990 to 2014 , especially those that bring guidelines to influence policies, programs and actions in the field of education in Brazil. We seek to understand, especially as multilateral organizations 
conceive and guide the integration of Information and Communication Technologies (ICT) in education in our country, based on, among others, the theoretical and conceptual contribution from: Dourado, Oliveira (2009); Mancebo, Mavés and Chaves (2006); Libâneo (201 1; 201 2); Sguissardi (2000); Lima (2005; 2013); Ferreira (2009; 201 2); Saviani (2008); Andreoli (2002). Documents are examined related to economic and educational issues relating to Latin America and the Caribbean, including, Brazil. It observe that there is a strong influence of multilateral organizations in Brazilian education and, in ICT, this guidance points to an expansion of the insertion and use of these technologies in all levels of education. These guidelines or guidance is based on a market and mechanistic logic of ICT, rather than a perspective that advocates greater democratization of access to information and knowledge, as well as a more critical education, and autonomous citizens.

Keywords: Education. Information and communication technologies. Multilateral organizations.

\section{Los organismos multilaterales y educación: la tecnología de la infor- mación y la comunicación (ICT) en cuestión}

\section{Resumen}

Este artículo analiza los organismos multilaterales de publicaciones desde 1990 hasta 2014, especialmente aquellos que traen directrices para influir en las políticas, programas y acciones en el campo de la educación en Brasil. Buscamos entender, sobre todo porque los organismos multilaterales concebir y orientar la integración de las Tecnologías de la Información y la Comunicación (TIC) en la educación en nuestro país, sobre la base de, entre otros, el aporte teórico y conceptual: Dourado, Oliveira (2009); Mancebo, Maués y Chaves (2006); Libâneo (201 1; 2012); Sguissardi (2000); Lima (2005; 2013 ); Ferreira (2009; 201 2); Saviani (2008); Andreoli (2002) Documentos producidos se examinan y se dirigen los asuntos económicos y educativos relacionados con América Latina y el Caribe, entre los cuales Brasil. Se observa que existe una fuerte influencia de los organismos multilaterales en la educación brasileña y, en TIC, estas directrices apuntan a la expansión de la inserción y el uso de estas tecnologías en todos los niveles de la educación. Estas directrices u orientaciones se basa en una lógica de mercado y mecanicista de las TIC, en lugar de una perspectiva que aboga por una mayor democratización del acceso a la información y el conocimiento, así como una educación más crítica, y ciudadanos autónomos.

Palabras clave: Educación. Tecnologías de la información y la comunicación. Organismos multilaterales. 
Organismos multilaterais e educação: As tecnologias da informação e comunicação (TIC) em questão

\section{Introdução}

Estudiosos que se preocupam com a educação e seus formatos no Brasil compreendem que diversos embates e visões de mundo compõem o atual cenário de reforma dos Estados. No âmbito das políticas e interferências internacionais, é preciso identificar quais são os compromissos para a área da educação firmados pelos organismos multilaterais e que concepções balizam tais políticas, pois os países em desenvolvimento são obrigados a incluir suas recomendações em relatórios e documentos, inclusive de empréstimos financeiros que contraírem com os Estados centrais (DOURADO; OLIVEIRA, 2009; MANCEBO; MAUÉS; CHAVES, 2006; SGUISSARDI, 2000).

Assim como Dourado e Oliveira (2009), neste estudo priorizamos a educação como política pública a ser assegurada mediante o aumento dos recursos que the são destinados, e defendemos a otimização da articulação entre as políticas e os programas de ações na área; a efetivação da gestão democrática em seus sistemas e escolas; e a consolidação de programas de formação, dentre outros. Porém, com a criação em 1996 da já extinta Secretaria de Educação a Distância (SEED/MEC) e do Programa TV Escola, assim como

220 com a criação do Programa Nacional de Informática na Educação (Proinfo) em 1997 (LIMA, 2005), começaram a ser implementadas diversas políticas públicas para a inclusão das tecnologias e das tecnologias da informação e comunicação (TIC) nas escolas e na educação superior, demonstrando ser essa uma das estratégias para o desenvolvimento da educação.

Assim, neste artigo, buscamos levantar e analisar as publicações de organismos multilaterais do período de 1990 a 2014, sobretudo, as que trazem orientações que visam influenciar as políticas, os programas e as ações no campo da educação no Brasil. Buscamos compreender, em especial, como os organismos multilaterais concebem e orientam a inserção das tecnologias da informação e comunicação (TIC) na educação em nosso país. São examinados os documentos direcionados às questões econômicas e educacionais de países da América Latina, bem como à educação no Brasil, com destaque para aqueles formulados pela Organização das Nações Unidas para a Educação, a Ciência e a Cultura (Unesco), pelo Banco Internacional para Reconstrução e Desenvolvimento (BIRD) e pelo Banco Mundial (BM). 


\section{Organismos multilaterais, TIC e educação no Brasil no período 1995-2014}

Alvim (2004) afirma que as instituições multilaterais são organizações internacionais surgidas de interesses corporativos e estatais de expansão comercial e que objetivam institucionalizar a cooperação econômica, social, cultural, científica e de segurança mútua entre as nações. Foram criadas, também, agências e comissões especializadas para tratar dos problemas econômicos, sociais e culturais.

Esses organismos multilaterais estão constituindo-se como agentes de interferência significativa para a expansão, inserção e uso das TIC no mundo, especialmente no âmbito da educação. São diversos os documentos e publicações que defendem e orientam a inserção e uso das TIC na educação em geral e na escola em particular, o que inclui a formação dos professores que irão utilizá-las. As diretrizes abrangem desde o uso do computador até o das tecnologias móveis e incluem as necessidades da escola e dos docentes e as novas atribuições dos alunos (crianças, adolescentes, jovens etc.) que precisam se adequar para ser incluídos nessa sociedade cada vez mais tecnológica.

Apesar da diversidade dos organismos multilaterais - Organização das Nações Unidas para a Educação, a Ciência e a Cultura (Unesco), Banco Mundial (BM), Banco Interamericano de Desenvolvimento (BIRD), Fundo Monetário Internacional (FMI), Programa das Nações Unidas para o Desenvolvimento (PNUD) e Organização Mundial do Comércio (OMC), dentre outros -, a maioria dos documentos que trazem orientações acerca do uso das TIC na educação é oriunda da Unesco, do BM e do BIRD.

A análise dos principais documentos desses organismos multilaterais ganha maior significado quando voltada para as políticas, programas e ações dos três últimos governos do Brasil: Fernando Henrique Cardoso (1 995-2002), Luiz Inácio Lula da Silva (2003-2010) e Dilma Vana Rousseff (201 1-2014). Cada um desses governos, guardadas suas especificidades, apresentou planos que objetivaram ampliar a inserção e o uso das TIC nos diferentes níveis e modalidades de educação. 
Organismos multilaterais e educação: As tecnologias da informação e comunicação (TIC) em questão

\section{Orientações e influências dos organismos multilaterais no período 1990- 2002}

Ao examinar o plano de governo de Fernando Henrique Cardoso (FHC), Ferreira (2012) afirma que nele foi dada continuidade ao processo de 'modernização' conservadora, que tem como base a racionalidade administrativa e a eficácia quantitativa, com início no governo de Fernando Collor de Mello (1990-1992) e de Itamar Franco (1992-1994). No governo Fernando Henrique Cardoso, conforme a autora, foram adotadas medidas para ajustes estruturais e fiscais, bem como implementadas reformas para a abertura de mercado, com vistas a integrar o país à economia mundial globalizada. Nessa direção, o mercado é considerado o portador das virtudes do crescimento e da geração de lucro, enquanto o Estado, sobretudo, o Estado burocrático, interventor e regulador, é visto como aquele que atrapalha o crescimento do país, e que, por isso, deve ter suas funções redimensionadas.

Lima (2013) pontua que fica evidente, no governo Fernando Henrique Cardoso (1994-2002), que a política educacional possui relação com uma proposta macroeconômica alicerçada em princípios neoliberais. A autora 222 afirma, ainda, que nesse governo, fortemente influenciado pela visão neoliberal e de democracia representativa, retoma-se o projeto da nova Lei de Diretrizes e Bases da Educação Nacional n. 9.394, de 20 de dezembro de 1996, mediante a aprovação da proposta apresentada pelo senador Darcy Ribeiro (LDB, Lei n. 9.394/1996), em detrimento da que havia sido elaborada pela sociedade civil. Conforme Oliveira (1997), a nova LDB estava embasada nas orientações neoliberais e dos organismos multilaterais, sobretudo, do BM.

$\bigcirc$ Quadro 1, a seguir, apresenta documentos que trazem orientações de organismos multilaterais para a educação no período 1990 a 2002, especialmente no governo Fernando Henrique Cardoso (1995-2002). São destacadas as propostas para a educação brasileira para a América Latina e Caribe, considerando, em especial, as destinadas ao uso das TIC. 
Daniela da Costa Britto Pereira Lima | João Ferreira de Oliveira | Tatiane Custódio da Silva Batista

\section{Quadro 1 \\ Principais documentos e publicações de organismos multilaterais no período de 1990 a 2002}

\begin{tabular}{|c|c|c|c|}
\hline Organismo & Documento & Descrição & Ano \\
\hline Unesco & $\begin{array}{l}\text { Declaração Mundial sobre } \\
\text { Educação para Todos }\end{array}$ & $\begin{array}{l}\text { Declaração mundial sobre educa- } \\
\text { ção para todos, com um plano de } \\
\text { ação a fim de satisfazer as neces- } \\
\text { sidades básicas de aprendizagem. } \\
\text { Reunião realizada em Jomtien } \\
\text { - Tailândia. }\end{array}$ & 1990 \\
\hline Banco Mundial & $\begin{array}{l}\text { La ensenãnza superior. } \\
\text { Las lecciones derivadas de } \\
\text { la experiência }\end{array}$ & $\begin{array}{l}\text { Destaca e divulga amplamente as } \\
\text { lições da experiência com o ensi- } \\
\text { no superior em muitos países, com } \\
\text { resultados de um grande número } \\
\text { de estudos de caso temáticos e } \\
\text { regionais. }\end{array}$ & 1995 \\
\hline Unesco & $\begin{array}{l}\text { Documento de Políitica para } \\
\text { el Cambio y el Desarrollo } \\
\text { en la Educación Superior }\end{array}$ & $\begin{array}{l}\text { Considera as principais tendências } \\
\text { no ensino superior, buscando formu- } \\
\text { lar a perspectiva da organização } \\
\text { nas questões políticas essenciais } \\
\text { nesse domínio. }\end{array}$ & 1995 \\
\hline Unesco & $\begin{array}{l}\text { Conferencia Mundial sobre } \\
\text { la Educación Superior. La } \\
\text { Educación Superior en el } \\
\text { siglo XXI }\end{array}$ & $\begin{array}{l}\text { Discute questões relativas ao ensino } \\
\text { superior, tendo em vista chegar a um } \\
\text { acordo sobre o tipo de educação su- } \\
\text { perior para o século seguinte. }\end{array}$ & 1998 \\
\hline$B I D$ & $\begin{array}{l}\text { Reforma de la educación } \\
\text { primaria y secundaria en } \\
\text { América Latina y el Caribe }\end{array}$ & $\begin{array}{l}\text { Resume o que é conhecido acer- } \\
\text { ca de como melhorar a educação } \\
\text { primária e secundária (termos do } \\
\text { documento) na América Latina e no } \\
\text { Caribe. Apresenta objetivos e estra- } \\
\text { tégias para guiar o BID em seu apoio } \\
\text { à educação na década seguinte. }\end{array}$ & 2000 \\
\hline Banco Mundial & $\begin{array}{l}\text { Brazil Higher Education } \\
\text { Sector Study Volume II }\end{array}$ & $\begin{array}{l}\text { A pedido do Ministro da Educação, } \\
\text { Paulo Renato, o Banco realizou uma } \\
\text { avaliação do estado do ensino supe- } \\
\text { rior e fez recomendações sobre sua } \\
\text { finalidade, estrutura, escopo, finan- } \\
\text { ciamento etc. }\end{array}$ & 2000 \\
\hline
\end{tabular}

Fonte | Elaborado pelos autores, com base nos documentos dos organismos multilaterais analisados. 
Organismos multilaterais e educação: As tecnologias da informação e comunicação (TIC) em questão

Segundo Saviani (2008), a década de 1990 foi palco de grandes transformações econômicas, que influenciaram e interferiram diretamente no sistema educacional e na concepção de educação, subsidiando o trabalho na escola. É possível perceber essa influência nos documentos examinados.

É a partir de 1990 que a Declaração Mundial sobre Educação para Todos (Unesco) ganha forte repercussão no Brasil, sobretudo, na formação de estudantes do ensino fundamental. Nesse documento afirma-se que

[...] mais de um terço dos adultos do mundo não têm acesso ao conhecimento impresso, às novas habilidades e tecnologias, que poderiam melhorar a qualidade de vida e ajudá-los a perceber e a adaptar-se às mudanças sociais e culturais (UNESCO, 1990, ([n.p.])

Assim, apesar de demonstrar que a tecnologia pode contribuir para a qualidade de vida, o documento apregoa que a sua contribuição está relacionada à adaptação, e não à transformação ou formação crítica e autônoma do educando pela educação, conforme defendemos neste estudo.

A Declaração Mundial sobre Educação para Todos enfatiza o 224 "aprender a aprender", que, segundo Saviani (2008, p. 170), está ligado à necessidade de atualização constante dos saberes. O documento da Unesco, ao considerar o grande acesso que se tem ao conhecimento hoje, enfatiza que tais conhecimentos "[...] incluem informações sobre como melhorar a qualidade de vida ou como aprender a aprender". Essa visão, conforme Saviani (2008), propagou-se na década de 1990.

O plano de ação do documento da Unesco (1990) tem como foco a "satisfação das necessidades básicas de aprendizagem", mas Libâneo (2012) mostra a contradição entre o que prega a Declaração Mundial sobre Educação para Todos e sua real intenção. Para o autor, quando o documento defende a garantia de acesso à educação, à saúde, à nutrição e ao trabalho, o que busca, na verdade, é assegurar políticas de ajuste estrutural para liberar as forças do mercado, transformando a cultura de direitos universais em bens e serviços básicos cobertos, em parte, pelo Estado. Ou seja, Libâneo (2012) entende que as políticas sociais são elaboradas para instrumentalizar a política econômica.

Outro texto da Unesco, "Documento de Política para el Cambio y el Desarrollo en la Educación Superior" (1995), afirma que a educação superior 
na década de 1990 estava em crise em praticamente todos os países do mundo. $\bigcirc$ documento acentua que

[...] el número de alumnos aumenta, pero la financiación pública disminuye, y aumenta también la distancia ya enorme que separa a países desarrollados y países en desarrollo en materia de enseñanza superior e investigación (UNESCO, 1995, p. 3).

Nesse documento também é dito que, para a renovação do ensino e da aprendizagem, é necessário melhorar a pertinência e a qualidade do ensino superior. Para isso, demonstram a necessidade de serem estabelecidos programas para provocar a

[...] capacidad intelectual de los estudiantes, mejorar el contenido interdisciplinario y multidisciplinario de los estudios y aplicar métodos pedagógicos que aumenten la eficiencia de la experiencia de aprendizaje, en especial teniendo en cuenta los rápidos avances de las tecnologías de la información y la comunicación (UNESCO, 1995, p. 9).

Por sua vez, o documento do Banco Mundial (1995, p. 8) "La ensenãnza superior, Las lecciones derivadas de la experiência" examina "[...] las principales dimensiones de la crisis que experimenta la enseñanza superior en los países en desarrollo, y se evalúan las perspectivas de éxito de las reformas". Nesse sentido, o documento afirma que as universidades educam os futuros dirigentes e preparam capacidades técnicas de alto nível, que contribuem para o crescimento econômico. Afirma ainda que os países em desenvolvimento têm investido em universidades e outras instituições de ensino superior com a ajuda e financiamento do Banco Mundial.

Entre outros pontos, o documento do BM defende que a ciência e tecnologia estejam presentes na formação primária, secundária e superior, porém, sempre na perspectiva de formar para o mercado.

El marco de políticas para la enseñanza superior necesita estar vinculado a condiciones nacionales específicas. Por ejemplo, las escalas de sueldos de la administración pública, las políticas de empleo y del mercado laboral, y el régimen nacional de inversiones en ciencia y tecnología tienen efectos decisivos en el desempeño y la evolución de las instituciones de enseñanza superior, lo mismo que la relación existente entre ellas y los subsectores de la educación primaria y secundaria (BANCO MUNDIAL, 1995, p. 74). 
Organismos multilaterais e educação: As tecnologias da informação e comunicação (TIC) em questão

Nota-se que os documentos da década de 1990 apresentam apreciações parecidas a respeito do acesso ao ensino superior, enfatizando o baixo investimento na área, e, por isso, pode-se afirmar que partem do pressuposto de que existe uma crise no ensino superior. Com relação a esse nível de ensino, a Conferência Mundial sobre la Educación Superior en el Siglo XXI, promovida pela Unesco (1998), dispõe que

[...] hay que utilizar plenamente el potencial de las nuevas tecnologías de la información y la comunicación para la renovación de la educación superior, mediante la ampliación y diversificación de la transmisión del saber, y poniendo los conocimientos y la información a disposición de un público más amplio. Ha de conseguirse el acceso equitativo a estas mediante la cooperación internacional y el apoyo a los países que no disponen de la capacidad de adquirir dichos instrumentos. La adaptación de estas tecnologías a las necesidades nacionales, regionales y locales y el suministro de sistemas técnicos, educativos, de gestión e institucionales para mantenerlas han de constituir una prioridad (UNESCO, 1998, p. 3).

Nos documentos citados, nota-se que a referência à necessidade de 226 formação para o uso das tecnologias vem ganhando cada vez mais destaque. As publicações e documentos apresentam as TIC como fundamentais para a formação escolar e para as novas demandas sociais, definindo o tema como uma das áreas críticas da reforma a ser efetivada na educação. Dessa forma, o documento do Banco Interamericano de Desenvolvimento (BID), "Reforma de la educación primaria y secundaria en América Latina y el Caribe", de 2000, afirma:

En este contexto, este documento resume la experiencia hasta la fecha y proporciona un conjunto de objetivos y estrategias para guiar al BID en el apoyo a la educación primaria y secundaria durante la próxima década. Se definen las cinco áreas críticas de la reforma - hacer que los maestros sean socios en el proceso de reforma, brindar más y mejores libros de texto y materiales, apoyar en forma selectiva el uso de la tecnología en la educación, descentralizar la administración educativa y tener una mayor rendición de cuentas por parte de los actores principales, así como también fortalecer la educación y desarrollo de la primera infancia (BANCO INTERAMERICANO DE DESENVOLVIMENTO, 2000, p. 31. 
Carvalho (201 1) destaca a publicação do documento "Brazil Higher Education Sector Study", no qual o Banco Mundial faz uma avaliação do ensino superior no Brasil. A autora traduz o seguinte trecho:

A pedido do Ministro da Educação, o Sr. Paulo Renato, o banco realizou uma avaliação da situação do ensino superior e fez recomendações sobre como sua finalidade, estrutura, escopo, financiamento e governança poderiam evoluir para melhor atender as necessidades do país (WORLD BANK apud CARVALHO, 2011, p. 60).

Ainda nessa direção, o documento reforça:

O objetivo principal dos participantes foi lançar um diálogo para mudança fundamental e de longo prazo, com base em uma avaliação equilibrada e realista, para onde se deve levar o ensino superior brasileiro (WORLD BANK apud CARVALHO, 201 1, p. 60).

A partir das duas últimas citações, fica evidente a influência e a permissão dada ao BM para interferir na educação brasileira, assim como propor direções a serem seguidas, sobretudo, no ensino superior.

\section{Orientações e influências dos organismos multilaterais no período 2003- 2010}

Ferreira (2009) afirma que a reforma da educação superior no governo Luiz Inácio Lula da Silva foi guiada pela promulgação de leis e decretos que refletem mais continuidade do que ruptura com as políticas de educação superior constituídas no governo Fernando Henrique Cardoso. Para a autora,

[...] o campo das políticas da educação superior foi desenvolvido tanto pelo governo FHC quanto pelo governo Lula, em consonância com parte das diretrizes emanadas pelos organismos multilaterais, procurando-se naturalizar a inexistência da contraposição entre os planos públicos e privados; a defesa do papel do Estado como regulador e controlador da prestação de contas das IES; a ciência e o conhecimento a serviço da economia, dentre outros (FERREIRA, 2012, p. 465). 
Organismos multilaterais e educação: As tecnologias da informação e comunicação (TIC) em questão

A autora salienta ainda que, mesmo com a iniciativa do Programa de Apoio a Planos de Reestruturação e Expansão das Universidades Federais (Reuni), uma proposta de expansão das universidades federais, evidenciam-se ações contraditórias, uma vez que medidas implantadas por Fernando Henrique Cardoso e mantidas por Luiz Inácio Lula da Silva são recomendadas pelo Banco Mundial (1 995), a exemplo do Fundo de Financiamento Estudantil (Fies) e do Programa Universidade Para Todos (ProUni), voltados para beneficiar o setor privado. Assim, conforme Ferreira (2009), o governo Luiz Inácio Lula da Silva optou por dar continuidade a várias ações do governo Fernando Henrique Cardoso, apesar de ter promovido uma mudança gradual na política educacional, uma vez que houve maior expansão das instituições de ensino públicas.

$\bigcirc$ Quadro 2 a seguir traz as orientações propostas pelos organismos multilaterais para a educação no período 2003-2010, destacando-se aquelas voltadas para a expansão e utilização das TIC no Brasil e demais países da América do Sul e do Caribe.

\section{Principais documentos e publicações de organismos multilaterais no período de} 2003 a 2010

\begin{tabular}{|l|l|l|c|}
\hline Organização & \multicolumn{1}{|c|}{ Documento } & \multicolumn{1}{c|}{ Descrição } & Ano \\
\hline Banco & $\begin{array}{l}\text { Construir Sociedades } \\
\text { de Conocimiento: } \\
\text { Nuevos Desafíos para } \\
\text { la Educación Terciaria }\end{array}$ & $\begin{array}{l}\text { Analisa a experiência do Banco } \\
\text { Mundial em relação ao ensino superior } \\
\text { e também de muitos intervenientes no } \\
\text { subsetor que estão fora do âmbito da } \\
\text { atividade do Banco. }\end{array}$ & 2003 \\
\hline Unesco & $\begin{array}{l}\text { Hacia las sociedades } \\
\text { del conocimiento }\end{array}$ & $\begin{array}{l}\text { Apresenta o panorama do futuro, } \\
\text { com características promissoras e e } \\
\text { inquietantes. }\end{array}$ & 2005 \\
\hline Unesco & $\begin{array}{l}\text { Marco estratégico para } \\
\text { a Unesco no Brasil }\end{array}$ & $\begin{array}{l}\text { Reflete sobre as tendências atuais no } \\
\text { contexto da cooperação internacional, } \\
\text { com o propósito de inaugurar uma nova } \\
\text { etapa, marcada por ações qualificadas } \\
\text { e à altura das novas exigências. }\end{array}$ & 2006 \\
\hline
\end{tabular}


Daniela da Costa Britto Pereira Lima | João Ferreira de Oliveira | Tatiane Custódio da Silva Batista

\begin{tabular}{|c|c|c|c|}
\hline Organização & Documento & Descrição & Ano \\
\hline Unesco & $\begin{array}{l}\text { Tecnologia, informação } \\
\text { e inclusão - acesso às } \\
\text { novas tecnologias }\end{array}$ & $\begin{array}{l}\text { Folhetos destinados a jornalistas, es- } \\
\text { tudantes e público em geral. Objetiva } \\
\text { estimular a disseminação de informação } \\
\text { e debate sobre a contribuição das no- } \\
\text { vas TIC para o desenvolvimento social } \\
\text { no Brasil. }\end{array}$ & 2008 \\
\hline Unesco & $\begin{array}{l}\text { Estándares de compe- } \\
\text { tencias en TIC para } \\
\text { docentes }\end{array}$ & $\begin{array}{l}\text { Marco de referência completo para um } \\
\text { modelo de utilização das TIC. Prevê a } \\
\text { criação de um mecanismo por parte } \\
\text { da Unesco destinado a aprovar pro- } \\
\text { gramas de formação que cumpram tais } \\
\text { modelos. }\end{array}$ & 2008 \\
\hline Unesco & $\begin{array}{l}\text { Padrões de compe- } \\
\text { tência em TIC para } \\
\text { professores - Módulos } \\
\text { de padrão de compe- } \\
\text { tência e Diretrizes de } \\
\text { implementação }\end{array}$ & $\begin{array}{l}\text { Busca fomentar discussões e debates } \\
\text { sobre a capacitação dos professores } \\
\text { para o uso de novas tecnologias em } \\
\text { sala de aula. O objetivo é apresentar } \\
\text { padrões de competência em TIC para } \\
\text { professores. }\end{array}$ & 2009 \\
\hline Unesco & $\begin{array}{l}\text { Padrões de compe- } \\
\text { tência em TIC para } \\
\text { professores - Marco } \\
\text { político }\end{array}$ & $\begin{array}{l}\text { Fomenta discussões e debates sobre a } \\
\text { capacitação dos professores para o uso } \\
\text { de novas tecnologias em sala de aula. } \\
\text { objetivo é apresentar as TIC como um } \\
\text { marco político. }\end{array}$ & 2009 \\
\hline
\end{tabular}

Fonte $\mid$ Elaborado pelos autores, com base nos documentos do Banco Mundial e da Unesco analisados

Em 2003, o Banco Mundial divulga o documento "Construir Sociedades de Conocimiento: Nuevos Desafíos para la Educación Terciária", que demonstra a necessidade de se construírem sociedades do conhecimento, destacando essa construção como desafio para a educação superior. Nesse sentido, o documento registra que as mudanças do século XXI podem significar ameaças ou oportunidades, já que a educação superior é forte e fundamental tanto para possibilitar capacidade intelectual e utilização do conhecimento como para promover práticas de aprendizagem contínua, tão necessária para atualizar conhecimentos e destrezas individuais. No documento, afirma-se ainda que 
Organismos multilaterais e educação: As tecnologias da informação e comunicação (TIC) em questão

[...] otro factor favorable es la aparición de nuevos tipos de instituciones terciarias y formas de competencia, que instan a las instituciones tradicionales a cambiar sus modos de operación y prestación de servicios, así como a aprovechar las oportunidades que ofrecen las nuevas tecnologías de la información y la comunicación (ICT, por su sigla en inglés) (BANCO MUNDIAL, 2003, p. 16).

Nesse período, as TIC são apresentadas no documento da Unesco "Hacia las sociedades del conocimiento" (2005) como fundamentais para a sociedade em geral, tendo em vista os avanços tecnológicos do século XX. Conforme o documento, as TIC

[...] han creado de hecho una nueva dinámica, porque desde mediados del siglo XX la formación de las personas y los grupos, así como los adelantos científicos y técnicos y las expresiones culturales, están en constante evolución, sobre todo hacia una interdependencia cada vez mayor (UNESCO, 2005, p. 5).

Esse documento da Unesco aborda a evolução das TIC e relaciona a necessidade de sua utilização constante pelas pessoas em seus cotidianos à influência que trazem para sua formação, podendo acarretar até mesmo dependência.

$\bigcirc$ "Marco estratégico para a Unesco no Brasil" (UNESCO, 2006) também apresenta as TIC como desafios para o novo século. Esse documento ressalta que, entre os desafios que o Brasil enfrenta na busca pelo desenvolvimento humano, se destacam:

A erradicação do analfabetismo, a melhoria da qualidade da educação, a redução da vulnerabilidade ambiental, dos conflitos sociais e da violência, a redução da pobreza, da miséria e da exclusão, a promoção da diversidade cultural e a generalização do acesso às novas tecnologias da informação e da comunicação (UNESCO, 2006, p. 9, grifo nosso).

As afirmações supracitadas indicam que os documentos internacionais indicam necessidades e trazem orientações a ser consideradas pelas políticas educacionais brasileiras, a partir de necessidades econômicas e do mercado. Dessa forma, notamos que a educação vem sendo orientada em conformidade com os avanços tecnológicos e os anseios do capitalismo. 
Outro documento da Unesco (2008), intitulado "Tecnologia, Informação e Inclusão", é composto por uma série de folhetos destinados aos jornalistas atuantes na mídia comunitária, a estudantes e ao público em geral. Trata-se de uma série composta por vários volumes, cujo intuito é estimular a disseminação da informação e também o debate sobre a contribuição das TIC para o desenvolvimento social no Brasil. A Unesco apresenta dados da TIC Domicílios, realizada em 2005 e 2006 pelo instituto Ipsos Opinion, a pedido do Comitê Gestor da Internet (CGI). Conforme essa pesquisa,

[...] mais da metade dos brasileiros $(54,4 \%)$ nunca usou um computador. Menos de $20 \%$ têm o equipamento em casa, e apenas $14,5 \%$ dos domicílios com computador estão ligados à rede mundial. Entretanto, 45,6\% dos entrevistados afirmaram já ter usado um computador, e $33 \%$ acessaram a internet pelo menos uma vez na vida - ou seja: 67\% nunca navegaram na internet (UNESCO, 2008, p. 11.

As reflexões acerca da necessidade de inserção e uso das TIC na educação brasileira, bem como na formação dos professores que irão utilizá-las em sala de aula e laboratórios, resultaram em outros documentos, elaborados tanto pelo BM como pela Unesco. $\bigcirc$ documento "Estándares de competencias en TIC para docentes" da Unesco (2008a) afirma que

[...] gracias a la utilización continua y eficaz de las TIC en procesos educativos, los estudiantes tienen la oportunidad de adquirir capacidades importantes en el uso de estas. El docente es la persona que desempeña el papel más importante en la tarea de ayudar a los estudiantes a adquirir esas capacidades. Además, es el responsable de diseñar tanto oportunidades de aprendizaje como el entorno propicio en el aula que facilite el uso de las TIC por parte de los estudiantes para aprender y comunicar. Por esto, es fundamental que todos los docentes estén preparados para ofrecer esas oportunidades a sus estudiantes (UNESCO, 2008a, p. 2).

Já no documento da Unesco "Padrões de competências em TIC", dividido em três cadernos lançados em 2009, o foco é a formação de competências do professor para o uso das TIC. Todos os cadernos trazem o mesmo prefácio em defesa das TIC, no qual se afirma que,

[...] para viver, aprender e trabalhar bem em uma sociedade cada vez mais complexa, rica em informação e baseada em conhecimento, os alunos e professores devem usar a tecnologia de forma 
Organismos multilaterais e educação: As tecnologias da informação e comunicação (TIC) em questão

efetiva, pois em um ambiente educacional qualificado, a tecnologia pode permitir que os alunos se tornem: usuários qualificados das tecnologias da informação; pessoas que buscam, analisam e avaliam a informação; solucionadores de problemas e tomadores de decisões; usuários criativos e efetivos de ferramentas de produtividade; comunicadores, colaboradores, editores e produtores; cidadãos informados, responsáveis e que oferecem contribuições (UNESCO, 2009, 2009a, 2009b, p. 3).

$\bigcirc$ que muda em cada caderno são os direcionamentos dados aos temas que cada um deles apresenta, mas todos estão relacionados às TIC e aos modos de potencializar seu uso na educação.

\section{Orientações e influências dos organismos multilaterais no período 2011 - 2014}

Lima (2013) destaca alguns pontos da proposta do governo de Dilma Vana Rousseff, reunidos no documento "Diretrizes do programa 2011 1-2014", que são apresentados como metas para a área da educação:

a) erradicação do analfabetismo no país; b) garantir a qualidade da educação básica brasileira; c) promover a inclusão digital, com banda larga, produção de material pedagógico digitalizado e formação de professores em todas as escolas públicas e privadas no campo e na cidade; d) expandir o orçamento da educação, ciência e tecnologia e melhorar a eficiência do gasto; e) consolidar a expansão da educação profissional, por meio dos Institutos Federais de Educação, Ciência e Tecnologia; fl tornar os espaços educacionais lugares de produção e difusão da cultura; dentre outras (LIMA, 2013, p. 129, grifo nosso).

Em relação ao ensino superior, Lima (2013) afirma que, até 2012, o governo Dilma Vana Rousseff tinha dado continuidade às políticas de expansão desse nível de ensino e de interiorização dos campi iniciadas no governo Luiz Inácio Lula da Silva. Destaca ainda a autora que, em ambos os casos, Dilma Vana Rousseff utilizou, inclusive, o mesmo programa, ou seja, o Programa de Apoio a Planos de Reestruturação e Expansão das Universidades Federais (Reuni).

Segundo Ferreira (2012), os governos Luiz Inácio Lula da Silva e Dilma Vana Rousseff optaram pelo referencial de reformas sociais, graças à política de estabilidade e ao crescimento da economia do país. Porém, precisamos nos 
atentar para o fato de esse discurso de política para a equidade ter começado no governo Fernando Henrique Cardoso, ganhando maior força no governo Luiz Inácio Lula da Silva, que ampliou sua importância e as áreas de atuação das políticas sociais. No primeiro governo Dilma Vana Rousseff, seguiu-se na mesma direção, e o discurso do crescimento econômico ganhou força, mas com a manutenção de programas sociais considerados fundamentais, a exemplo do Minha Casa Minha Vida e do Bolsa Família. Dois outros programas fundamentais desse governo foram o Ciências sem Fronteiras e o Programa Nacional de Acesso ao Ensino Técnico e Emprego (Pronatec).

$\bigcirc$ Quadro 3 a seguir apresenta os principais documentos dos organismos multilaterais e suas ênfases nos anos de 2013 e 2014.

\section{Quadro 3}

\section{Principais documentos e publicações de organismos multilaterais nos anos de 2013 e 2014}

\begin{tabular}{|c|c|c|c|}
\hline Organização & Documento & Descrição & Ano \\
\hline Unesco & $\begin{array}{l}\text { Recursos educacionais } \\
\text { abertos no Brasil, o es- } \\
\text { tado da arte, desafios } \\
\text { e perspectivas para } \\
\text { o desenvolvimento e } \\
\text { inovação. }\end{array}$ & $\begin{array}{l}\text { Estado da Arte dos Recursos Educacionais } \\
\text { Abertos (REA) no Brasil, de } 201 \text { 1, implanta- } \\
\text { do por iniciativa do Instituto para a aplicação } \\
\text { das tecnologias da informação à educação, } \\
\text { da Unesco em Moscou (Institute of Information } \\
\text { Technologies in Education - Unesco llTE). }\end{array}$ & 2013 \\
\hline Unesco & $\begin{array}{l}\text { Enfoques estratégicos so- } \\
\text { bre las TIC en educación } \\
\text { en América Latina y el } \\
\text { Caribe }\end{array}$ & $\begin{array}{l}\text { Propõe ideias para o desenho de um novo } \\
\text { paradigma educacional para os países latino- } \\
\text {-americanos e do Caribe. }\end{array}$ & 2014 \\
\hline Unesco & $\begin{array}{l}\text { O futuro da aprendiza- } \\
\text { gem móvel - Implicações } \\
\text { para planejadores e ges- } \\
\text { tores de políticas }\end{array}$ & $\begin{array}{l}\text { Trata da aprendizagem móvel, com vistas a } \\
\text { melhorar a compreensão e utilização das tec- } \\
\text { nologias móveis para melhorar o acesso, a } \\
\text { equidade a qualidade da educação no mun- } \\
\text { do. Desenvolvido em parceria com a Nokia. }\end{array}$ & 2014 \\
\hline Unesco & $\begin{array}{l}\text { Diretrizes de políticas da } \\
\text { Unesco para a aprendi- } \\
\text { zagem móvel }\end{array}$ & $\begin{array}{l}\text { Informa sobre o ideal de indivíduos, orga- } \\
\text { nizações e governos atuarem juntos para a } \\
\text { produção de diretrizes. Teve a contribuição fi- } \\
\text { nanceira da Nokia. }\end{array}$ & 2014 \\
\hline
\end{tabular}

Fonte | Elaborado pelos autores, com base nos documentos do Banco Mundial e da Unesco analisados. 
Organismos multilaterais e educação: As tecnologias da informação e comunicação (TIC) em questão

A obra sobre o estado da arte dos Recursos Educacionais Abertos (REA) no Brasil teve como objetivo disseminar as experiências desenvolvidas em alguns países não falantes de língua inglesa para a comunidade internacional. $\bigcirc$ documento é um relatório de ações e possibilidades dos Recursos Educacionais Abertos (REA), e, por isso,

[...] são feitas diversas recomendações sobre o uso de REA no ensino básico e superior, aplicáveis tanto ao sistema privado como ao público. Foram resumidos a importância e o papel de diversas questões relacionadas ao desenvolvimento e implementação de REA, como tecnologia, pedagogia, direitos autorais, política e controle de qualidade. Se essas recomendações forem seguidas, os REA têm o potencial de facilitar extensivas inovações em todo o sistema educacional brasileiro, elevando o padrão das oportunidades de aprendizagem para a juventude e para a futura força de trabalho do país (UNESCO, 2013, p. 14).

Dentre os documentos voltados para o uso das TIC citados no Quadro 3, também destacamos o "Enfoques estratégicos sobre las TIC en educación en América Latina y el Caribe" (2014a). Esse documento é resultado de diversas 234 discussões relacionadas às práticas educativas e à avaliação de aprendizagem, refletindo sobre a necessidade de sua atualização. Nele, considera-se que

[...] el desarrollo que han alcanzado las TIC (Tecnologías de la Información y la Comunicación) en los últimos años demanda al sistema educacional una actualización de prácticas y contenidos que sean acordes a la nueva sociedad de la información (UNESCO, $2014 a$, p. 8).

De acordo com esse documento da Unesco, a utilização das TIC é, ao mesmo tempo, uma oportunidade e um desafio que impõem a tarefa de encontrar para essas tecnologias um sentido e uso que permita desenvolver uma sociedade mais democrática e inclusiva. Também considera que as novas gerações vivem uma intensa relação com as tecnologias digitais, pois são jovens que não conheceram o mundo sem internet. Para eles, portanto, as tecnologias digitais são mediadoras de grande parte de suas vivências.

Conforme as considerações da Unesco (2014a, p. 17), esses jovens estão desenvolvendo competências distintas, pois adquirem muita informação 
fora da escola; tomam rápidas decisões e são acostumados a ter respostas quase instantâneas quando desafiados; e têm uma capacidade de processamento paralelo, pois são altamente multimídia e parecem aprender de maneira diferente. Conforme o documento, as escolas enfrentam "[...] la necesidad de innovar en los métodos pedagógicos si desean convocar y ser inspiradoras para las nuevas generaciones de jóvenes".

Outro documento específico para o uso das TIC é "O futuro da aprendizagem móvel - Implicações para planejadores e gestores de políticas" (20 14). O mais interessante é que, nessa reflexão, o parceiro da Unesco foi a Nokia, uma empresa privada de telecomunicações. Como parte da série "Documentos de trabalho sobre aprendizagem móvel", da Unesco, indica que é preciso buscar uma melhor compreensão de como as tecnologias móveis podem ser utilizadas para melhorar o acesso à educação, bem como sua equidade e qualidade no mundo todo.

São 14 documentos independentes publicados em 2012 e 2013 - "O futuro da aprendizagem móvel - Implicações para planejadores e gestores de políiticas" é o primeiro disponível em português -, divididos em duas subséries:

Seis documentos tratam sobre iniciativas de aprendizagem móvel e suas implicações em termos de políticas públicas, e os outros seis investigam maneiras em que as tecnologias móveis podem ajudar professores a melhorar suas práticas (UNESCO, 2014, p. 5).

De acordo com a Unesco $(2014$, p. 5), "[...] a série fornece um retrato atual dos esforços que estão sendo feitos no mundo inteiro para promover a aprendizagem móvel".

Em "Diretrizes de políticas da Unesco para a aprendizagem móvel" (2014b), encontra-se a compreensão de que as tecnologias móveis podem enriquecer e ampliar possibilidades educacionais para estudantes em diversos ambientes. Esse conjunto de diretrizes

[...] visa a auxiliar os formuladores de políticas a entender melhor o que é aprendizagem móvel e como seus benefícios, tão particulares, podem ser usados como alavanca para fazer avançar o progresso em direção à Educação para Todos (UNESCO, 2014b, p. 6). 
Organismos multilaterais e educação: As tecnologias da informação e comunicação (TIC) em questão

Nesse contexto, cabe retomar as Diretrizes Curriculares Nacionais do Ensino Fundamental (DCNEF, 2010), que afirmam que as TIC estão presentes no cotidiano dos alunos e têm alterado suas relações sociais. As Diretrizes Curriculares Nacionais do Ensino Fundamental (DCNEF) orientam que essas tecnologias devem ser consideradas como instrumentos importantes para a aprendizagem dos alunos e que o professor tenha capacidade de utilizá-las e tratá-las como recursos e ferramenta pedagógica em diversas situações. Segundo o documento, com essa perspectiva de atuação, o docente será capaz de desenvolver nos alunos habilidades intelectuais e atitudes necessárias para a vida.

É importante destacar que as DCNEF consideram a escola e o professor como fundamentais para auxiliar os alunos no uso das tecnologias, e, por isso, estão em conformidade com os documentos da Unesco. As Diretrizes recomendam que os professores devem valer-se desses recursos, sempre que possível, para a formação de cidadãos que utilizem as tecnologias de forma crítica, mas enfatizam que, para tanto, eles devem receber formação qualificada e contar com recursos adequados e suficientes para trabalhar com todos os alunos (BRASIL, 2010).

236 Notamos que a informação e a comunicação também continuam a serviço do capital, agora de uma forma renovada, que, segundo Bolaño (1997), se adequa às exigências da modernização do fim do século XX, abrindo-se para a expansão no século XXI. Para o autor, o desenvolvimento capitalista levou a sociedade à internet e desta já não pode prescindir. Trata-se do velho capitalismo se reorganizando, articulando a produção, o armazenamento e a circulação das informações.

Saviani (2008, p. 168) pontua que a pedagogia produtivista - que considera a educação como um bem de produção, e não somente como um bem de consumo, tendo assim grande importância no processo de desenvolvimento econômico - sempre esteve relacionada à pedagogia tecnicista no Brasil, sob a qual os indivíduos assumem comportamentos flexíveis para serem ajustados às necessidades da sociedade. $\bigcirc$ autor mostra que essa concepção produtivista da educação permanece hegemônica e possui uma dupla face: a externa, em que a educação é importante para o processo de produção econômica; e a interna, que "[...] visa dotar a escola de um alto grau de produtividade, potencializando os investimentos nela realizados". Assim, para o 
autor, essa concepção pedagógica vê a escola como instituição reprodutora do capital e visa mais resultados com menor investimento.

Na contramão da supervalorização das TIC, observada nos documentos analisados, Libâneo (2011) considera o uso das tecnologias como instrumentos, e não como finalidade da educação. Nessa direção, afirma:

Obviamente, não sou contra o uso das tecnologias da educação. Sou contra a fetichização das tecnologias e seu uso apenas para formar professores em massa e em tempo reduzido, com um programa meramente instrumental. $\bigcirc$ professor 'tarefeiro' deixa de ser sujeito, o lugar dos sujeitos passa a ser atribuído à tecnologia. Acredito que a formação do professor inclui, evidentemente, uma instrumentação, a apropriação das tecnologias. Mas, antes disso, o professor precisa dominar bem os conteúdos, ter uma formação cultural sólida e uma visão crítica do seu trabalho e da sociedade (LIBÂAEO, 2011 , p. 90).

Assim, há de se refletir ainda sobre a relação das tecnologias com os conteúdos, ou melhor, em como utilizar essas tecnologias para melhorar o ensino e despertar o interesse e a aprendizagem do aluno. Para Libâneo (1998), a formação cultural básica é o suporte da educação tecnológica, e os efeitos que as tecnologias trazem ao processo educativo supõem mediações cognitivas e interativas que acontecem na relação professor - aluno.

\section{Considerações finais}

Os organismos multilaterais vêm direcionando, ao longo de décadas, as políticas, os programas e as ações no campo da educação no Brasil. Os documentos analisados mostram as políticas e ações que devem ser adotadas no país. O Brasil, assim como os países pobres e em desenvolvimento, assume, em geral, uma posição de adesão ou de mera subordinação às diretrizes e determinações dos organismos multilaterais, em prejuízo da autonomia e do projeto democrático e inclusivo da nação. Tais orientações, mesmo sem as condicionalidades decorrentes de empréstimos dos organismos multilaterais, são adotadas como adequadas para o nosso país, o que inclui as direcionadas às tecnologias da informação e comunicação (TIC). As orientações estão assentadas nas transformações do capitalismo globalizado em curso, o que acentua 
Organismos multilaterais e educação: As tecnologias da informação e comunicação (TIC) em questão

a lógica mercantil e mecanicista das $\mathrm{TIC}$, em detrimento de uma perspectiva que defende uma maior democratização do acesso à informação e ao conhecimento, bem como uma formação escolar mais crítica, autônoma e cidadã.

$\bigcirc$ estudo dos documentos dos organismos multilaterais evidencia, pois, que há forte determinação de suas orientações na educação brasileira e que, no âmbito das TIC, indicam para a expansão da inserção e uso dessas tecnologias em todos os níveis educacionais. $\bigcirc$ propósito em geral não é a formação mais ampla, consistente, autônoma e crítica de professores e estudantes, ou mesmo uma melhor qualificação da gestão e da coordenação do trabalho escolar, visando uma inserção cidadã, e sim a mera aquisição e difusão de tecnologias que atendam interesses diversos.

A partir dos documentos, percebemos que há direcionamentos específicos para as tecnologias, assim como para a educação em geral, principalmente a educação superior, nível no qual os organismos multilaterais consideram ser indispensável o uso das TIC no processo de formação. As principais propostas foram formuladas pela Unesco e defendem a educação, a ciência e a cultura, no sentido de construir uma sociedade do conhecimento, propondo avaliações e padrões de qualidade para a educação e para o uso 238 das TIC na escola e pela sociedade em geral.

O governo Fernando Henrique Cardoso (1995-2002) foi marcado por uma orientação neoliberal voltada para o crescimento econômico. Coerentes com essa orientação, os documentos analisados propõem: satisfazer as necessidades básicas de aprendizagem; desenvolver a educação superior (como potencialidade econômica); ampliar a educação para todos; introduzir as TIC em todos os níveis e modalidades de ensino; melhorar a educação primária; e promover a avaliação externa, entre outras ações que se relacionam com as diretrizes neoliberais, principalmente as de eficiência e equidade.

No governo Luiz Inácio Lula da Silva (2003-2010), há certa continuidade em relação à lógica que orientou o governo anterior, principalmente as políticas de educação superior voltadas para a expansão das instituições privadas. Mas também a expansão das Instituições Federais de Ensino Superior (IFES) foi implementada, a exemplo do Programa de Apoio a Planos de Reestruturação e Expansão das Universidades Federais (Reuni).

Em relação ao primeiro mandato do governo Dilma Vana Rousseff (201 1-2014), observam-se menos propostas dos organismos multilaterais. O 
Daniela da Costa Britto Pereira Lima | João Ferreira de Oliveira | Tatiane Custódio da Silva Batista

programa desse governo propôs melhorar a qualidade da educação básica brasileira; promover a inclusão digital; expandir o orçamento da educação e a formação profissional; e desenvolver a ciência, a tecnologia e a inovação, entre outras ações.

Nesse período (200 1-2014), a Unesco teve certo protagonismo na edição de documentos orientadores, a exemplo da utilização de Recursos Educacionais Abertos (REA) no Brasil e de propostas de um novo paradigma educacional para os países latino-americanos e do Caribe. Destacamos os documentos orientados pelo mercado, ou seja, mediante parceria com uma empresa privada de telecomunicações, a Nokia, que visam a melhoria da utilização das tecnologias móveis e a facilidade de acesso a elas, garantindo sua equidade, bem como a qualidade da educação no mundo. Outras diretrizes visam a auxiliar os formuladores de políticas na compreensão dos benefícios da aprendizagem móvel, bem como sobre a possibilidade que abrem para contribuir para a educação para todos. Em virtude de terem sido elaborados em parceria com uma empresa da iniciativa privada, os documentos propõem medidas que contribuem para fortalecer o capitalismo, tais como a proposta de equidade e do uso das TIC para o acesso à educação.

Nesse contexto, é preciso retomarmos a afirmação de Libâneo (2012) de que as políticas educacionais promovidas e mantidas pelo Banco Mundial (BM) e pelos organismos multilaterais em geral, principalmente a partir dos anos 1990, assumem uma educação voltada para a reestruturação capitalista. $\bigcirc$ autor destaca que as reformas propostas a países como o Brasil instalaram o pensamento único no campo das políticas educacionais, no qual prevalece a lógica da sociedade de livre mercado.

Neste estudo pudemos notar que são visíveis as influências dos organismos multilaterais nas políticas e ações para a educação brasileira, o que se reflete em grande medida na definição das políticas internas, na alocação de recursos e na formação escolar em todos os níveis e modalidades. Essas influências visam moldar as competências dos educandos para o trabalho e para o consumo, em um contexto de globalização econômica e de acumulação capitalista.

Percebemos, pois, que tais documentos buscam influenciar as decisões educacionais no Brasil e estabelecer formulações básicas para a educação, com uma grande ênfase na formação tecnológica e mercadológica, tão 
Organismos multilaterais e educação: As tecnologias da informação e comunicação (TIC) em questão

valorizada pelo modo de produção capitalista, sobretudo, com a aquisição de competências flexíveis (gerais e específicas) que contribuam para ajustar os trabalhadores e consumidores a um mundo em permanente mutação.

É preciso superar, como destaca Andreoli (2002), o que o Banco Mundial apresenta como tarefa da educação, ou seja, a de atender o capitalismo. Os organismos multilaterais propõem, conforme o autor, a utilização das TIC na educação como geradoras de trabalho e consumo para ampliar o mercado consumidor e gerar estabilidade nas políticas dos países periféricos para que os processos educativos se subordinem aos interesses da reprodução das relações sociais capitalistas.

Tudo isso nos leva à compreensão de que precisamos pensar o Brasil e sua educação numa perspectiva de soberania nacional, no tocante à definição das políticas educacionais. Estas devem estar articuladas a um projeto de educação emancipadora, que contribua para a formação cidadã e para a elevação intelectual e cultural de nossa gente, especialmente dos menos favorecidos socialmente.

Finalmente, julgamos que a análise das orientações dos documentos analisados irá contribuir para o repensar das concepções de tecnologias constantes nas políticas educacionais brasileiras, atentando para o foco que tem sido dado pelos programas e ações dos organismos multilaterais, de forma a que se supere o atendimento ao mercado. $O$ ponto de partida dessas ações deve estar no pressuposto de que as tecnologias não podem ser vistas separadamente da sociedade e da cultura, porque abrangem interações e valores humanos. Por isso, acreditamos que a formação para a inclusão digital e tecnológica deve ter como fundamento a práxis na produção de conhecimento, na interação, na troca de informação, no acesso irrestrito às informações, em favor do conhecimento de todos, ou seja, para a transformação social, crítica e política dos indivíduos.

\section{Referências}

ALVIM, Valdir. Neoliberalismo, globalização e americanismo: as estratégias dos organismos financeiros multilaterais. Revista Katálysis, Florianópolis, v. 7, n. 1, 2004. Semestral. Disponivel em: http://www.redalyc.org/articulo.oa?id=179617802009. Acesso em: 17 jan. 2015. 
ANDREOLI, Antônio Inácio. As políticas educacionais no contexto do neoliberalismo. Revista Espaço Acadêmico, Maringá, n. 13, 2002. Disponível em: http://www.espacoacademico.com.br/013/13andrioli.htm. Acesso em: 10 jan. 2016.

Banco Interamericano de Desenvolvimento. Reforma de la educación primaria y secundaria en América Latina y el Caribe. 2000. Disponível em: http://idbdocs.iadb.org/wsdocs/ getdocument.aspx?docnum=1448768. Acesso em: 5 jul. 2015.

Banco Mundial. La educación superior: Las enseñanzas de la experiencia: La enseñanza superior: Las lecciones derivadas de la experiência, 1995. Disponível em: http://www-wds.worldbank.org/external/default/WDSContentServer/WDSP/IB/2005/06/14/00 0090341_20050614161209/Rendered/PDF/133500PAPEROSp 1 riorOBox2150A 199 5001 .pdf. Acesso em: 5 jul. 2015.

BOLAÑO, César. A convergência informática/telecomunicações/audiovisual. Praga. Revista de estudos marxistas. São Paulo, v. 4, p. 67-77, 1997.

BRASIL. Conselho Nacional de Educação (CNE). Resolução CNE/CEB n. 7, de 14 de dezembro de 2010. Fixa as Diretrizes Curriculares Nacionais do Ensino Fundamental. Brasília, 2010.

BRASIL. Lei de Diretrizes e Bases da Educação Nacional. Lei n. 9.394, de 20 de dezembro de 1996. Estabelece as diretrizes e bases da educação nacional. Brasília, 2010.

CARVALHO, Cristina Helena Almeida de. A política pública para a educação superior no Brasil (1995-2008): ruptura e/ou continuidade? 2011. 465f. Tese (Doutorado em Economia). Programa de Pós-Graduação em Ciências Econômicas, Instituto de Economia, Universidade Estadual de Campinas. Campinas, 2011.

DOURADO, Luiz Fernandes; OLIVEIRA, João Ferreira de. A qualidade da educação: perspectivas e desafios. Cadernos Cedes, Campinas, v. 29, n. 78, p. 201-2015, 2009. Quadrimestral.

FERREIRA, Suely. A universidade do século XXI: concepções, finalidades e contradições. 2009, 303f. (Doutorado em Educação). Programa de Pós-Graduação em Educação, Faculdade de Educação, Universidade Federal de Goiás. Goiânia, 2009.

Reformas na Educação Superior: de FHC a Dilma Rousseff (1995-2011). Linhas Críticas, Brasília, n. 36, v. 18, maio/ago. 2012. Disponível em: http://periodicos.unb.br/ index.php/linhascriticas/article/view/6794. Acesso em: 2 jan. 2013. 
Organismos multilaterais e educação: As tecnologias da informação e comunicação (TIC) em questão

LIBÂNEO, José Carlos. Profissão professor ou adeus professor, adeus professora? Exigências educacionais contemporâneas e novas atitudes docentes. In:

Adeus professor,

adeus professora? Novas exigências educacionais e profissão docente. São Paulo: Cortez, 1998. Disponível em: http://www.luciavasconcelos.com.br/novo/professor/index2. php?option=com_docman\&task=doc_view\&gid=1471\&ltemid=31. Acesso em: 12 maio 2014.

Escola pública brasileira, um sonho frustrado: falharam as escolas ou as políticas educacionais. In: SUANNO, Marilza Vanessa Rosa. Didática e escola em uma sociedade complexa. Goiânia: CEPED, 2011.

dualismo perverso da escola pública brasileira: escola do conhecimento para os ricos, escola do acolhimento social para os pobres. Educação e Pesquisa, São Paulo, v. 38, n. 1, p. 13-28, 2012. Trimestral. Disponível em: http://www.scielo.br/pdf/ep/v38n 1/ aop323. Acesso em: set. 2014.

LIMA, Daniela da Costa Britto Pereira. Estratégias cognitivas do professor na aprendizagem do uso do software Everest: contribuições para uma metodologia de formação docente. 2005, 169f. Dissertação (Mestrado em Educação), Programa de Pós-Graduação em Educação Brasileira, Faculdade de Educação, Universidade Federal de Goiás. Goiânia, 2005

Políticas públicas de EaD no ensino superior: uma análise a partir das capacidades do Estado. 201 3, 286f. Tese (Doutorado em Políticas Públicas, Estratégias e Desenvolvimento). Programa de Pós-Graduação em Políticas Públicas, Estratégias e Desenvolvimento, Instituto de Economia, Universidade Federal do Rio de Janeiro. Rio de Janeiro, 2013.

MANCEBO, Deise; MAUÉS, Olgaíses; CHAVES, Vera Lúcia Jacob. Crise e reforma do Estado e da Universidade Brasileira: implicações para o trabalho docente. Educar, Curitiba, n. 28, p. 37-53, set./dez. 2006.

OLIVEIRA, R. T. C. de. A LDB e o contexto nacional: o papel dos partidos políticos na elaboração dos projetos - 1988-1996. Tese (Doutorado). Programa de Pós-Graduação em Educação, Faculdade de Educação. Universidade Estadual de Campinas. Campinas, 1997.

SAVIANI, Demerval. A pedagogia no Brasil: história e teoria. Campinas: Autores Associados, 2008.

SGUISSARDI, Valdemar. $\bigcirc$ Banco Mundial e a educação superior: revisitando teses e posições? Universidade e Sociedade, Brasília, v. 10, n. 22, p. 66-77, 2000. 
Daniela da Costa Britto Pereira Lima | João Ferreira de Oliveira | Tatiane Custódio da Silva Batista

UNESCO. Declaração Mundial sobre Educação para Todos: satisfação das necessidades básicas de aprendizagem. Jomtien, 1990. Disponível em: http://unesdoc.unesco.org/ images/0008/000862/086291 por.pdf. Acesso em: 8 jul. 2015.

Documento de Política para el Cambio y el Desarrollo en la Educación Superior.

1995. Disponível em: http://www.uv.mx/meif/files/2015/03/Documento-de-politicapara-el-cambio-y-desarrollo-de-la-ES.pdf. Acesso em: 10 jul. 2015.

- Conferencia Mundial sobre la Educación Superior. La Educación Superior en el siglo XXI. 1998. Disponívelem: http://unesdoc.unesco.org/images/001 1/001 163/1 16345s. pdf. Acesso em: 7 jul. 2015.

Hacia las sociedades del conocimiento. 2005. Disponível em: http://unesdoc. unesco.org/images/0014/001419/141908s.pdf. Acesso em: 8 jul. 2015.

Marco Estratégico para a UNESCO no Brasil. 2006. Disponível em: http://www. adur-ri.org.br/4poli/gruposadur/gtpe/marco_estrategico_unesco_educ_brasil.pdf. Acesso em: 6 jul. 2015.

Tecnologia, informação e inclusão - acesso às novas tecnologias, 2008. Disponível em: http://unesdoc.unesco.org/images/0015/001585/158502por.pdf. Acesso em: 7 jul. 2015.

Estándares de competencias en TIC para docentes. 2008a. Disponível em: http:// www.oei.es/tic/UNESCOEstandaresDocentes.pdf. Acesso em: 5 jul. 2015.

Padrõesdecompetênciaem TICparaprofessores-módulos depadrãodecompetência, 2009. Disponível em: http://unesdoc.unesco.org/images/0015/001562/156207por. pdf. Acesso em: 7 jul. 2015.

Padrões de competência em TIC para professores - Diretrizes de implementação. 2009a. http://unesdoc.unesco.org/images/0015/001562/156209por.pdf. Acesso em: 5 jul. 2015.

Padrões de competência em TIC para professores - marco político. 2009b. Disponível em: http://unesdoc.unesco.org/images/0015/001562/156210por.pdf. Acesso em: 6 jul. 2015.

Clausura de la conferencia mundial de educación superior (CMES). 2009c. Disponível em: http://www.iesalc.unesco.org.ve/index.php?option=com_content\&view=a rticle\&id=576\%3Aboletin-especial-iesalc-informa-no-194-1 o-dia-de-la-conferencia-mundial-de- 
Organismos multilaterais e educação: As tecnologias da informação e comunicação (TIC) em questão

-educacion-superior\&catid=101\%3Adestacados\&ltemid=450\&lang=es. Acesso em: 8 jul. 2015.

Recursos educacionais abertos no Brasil o estado da arte, desafios e perspectivas para o desenvolvimento e inovação. 2013. Disponível em: http://unesdoc.unesco.org/ images/0022/002279/227970por.pdf. Acesso em: 8 jul. 2015.

O futuro da aprendizagem móvel - implicações para planejadores e gestores de políticas. 2014. Disponível em: http://unesdoc.unesco.org/ images/0022/002280/228074POR.pdf. Acesso em: 8 jul. 2015.

Enfoques estratégicos sobre las TIC en educación en América Latina y el Caribe.

2014. Disponível em: http://www.unesco.org/new/fileadmin/MULTIMEDIA/FIELD/ Santiago/images/ticsesp.pdf. Acesso em: 13 mar. 2015.

Diretrizes de políticas da UNESCO para a aprendizagem móvel. 2014b. Disponível em: http://unesdoc.unesco.org/images/0022/002277/227770por.pdf. Acesso em: 8 jul. 2015.

WORLD BANK. Brazil Higher Education Sector Study. 2000. (v. II). Disponível em: hitp:// www-wds.worldbank.org/external/default/WDSContentServer/WDSP/IB/2000/08/1 244 8/000094946_00080105302141/Rendered/PDF/multi_page.pdf. Acesso em: 5 jul. 2015 .

Construir sociedades de conocimiento: nuevos desafíos para la educación terciaria, 2003. Disponível em: http://siteresources.worldbank.org/TERTIARYEDUCATION/ Resources/Documents/Constructing-Knowledge-Societies/CKS-spanish.pdf. Acesso em: 7 jul. 2015.

Profa. Dra. Daniela da Costa Britto Pereira Lima Universidade Federal de Goiás Faculdade de Educação | UFG

Programa de Pós-Graduação em Educação | UFG Pesquisadora do Grupo de Pesquisa CNPq: Estado e Políticas Educacionais e Coordenadora do Grupo de Estudos em Educação a Distância - FE|UFG E-mail | professoradanielalima@gmail.com 
Profa. Mestranda Tatiane Custódio da Silva Batista Secretaria Municipal de Educação de Anápolis/Goiás Programa de Pós-Graduação Interdisciplinar em Educação, Linguagem e Tecnologias Pesquisadora do Grupo de Pesquisa CNPq: Estado e Políticas Educacionais e participante do Grupo de Estudos em Educação a Distância - FE|UFG E-mail | tatiane_custodio_silva@hotmail.com

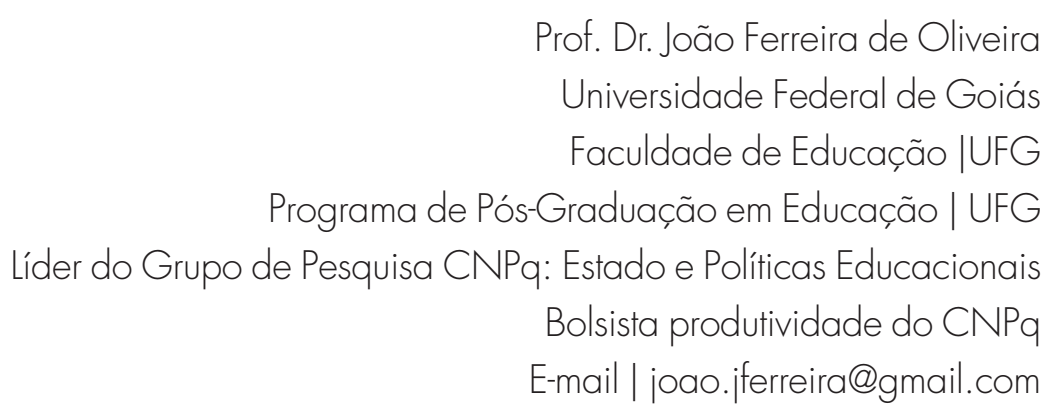

Recebido 25 abr. 2016

Aceito 4 ago. 2016 